\title{
Interação vírus/vetor para pulgões (Hemiptera: Aphididae) e mosca-branca (Hemiptera: Aleyrodidae)
}

Alexandre Moisés Ericsson de Oliveira ${ }^{1}$, Léia Cardoso ${ }^{2}$, Débora Baleeiro de Carvalho Ericsson ${ }^{3}$, Mauro Aparecido de Sousa Xavier ${ }^{4}$, Thaís Ferreira Bicalho ${ }^{5}$, Alessandra Rejane Ericsson de Oliveira Xavier ${ }^{6 *}$

\begin{abstract}
Resumo
O impacto provocado por afídeos e mosca-branca, tem crescido consideravelmente nas últimas décadas, devido ao aumento nos casos de surtos populacionais destas pragas que são transmissoras de vírus em diversas culturas de importância econômica. A aquisição e a transmissão da maioria dos vírus fitopatogênicos por um inseto vetor é o ponto central para o ciclo de uma infecção. Os vírus de plantas podem interagir com seus hospedeiros de insetos em uma variedade de formas, em alguns casos inclusive a replicação do vírus pode ocorrer em células do inseto. A interação do vírus com seus inseto hospedeiro/vetor requer interações moleculares específicas entre vírus e hospedeiro, comumente via proteínas, no entanto, quais componentes do vetor estão envolvidos e como eles funcionam para facilitar a transmissão ainda não está bem entendido. O objetivo do presente trabalho foi realizar uma revisão sistemática sobre as relações básicas de vírus/vetor em afídeos e mosca-branca; mostrar as práticas utilizadas atualmente no manejo integrado de pragas para afídeos e mosca-branca, além disso, relatar como as interações vetoriais de inseto estão abrindo novas portas para o controle de insetos vetores de vírus de plantas com o uso de novas tecnologias genéticas e computacionais. O presente estudo seguiu a metodologia de revisão sistemática, o trabalho foi conduzido em etapas que envolveram o desenvolvimento do protocolo de revisão com as questões da pesquisa, a estratégia de busca, a identificação dos critérios de inclusão e exclusão, a busca nas bases de dados previamente definidas, avaliação crítica, extração dos dados relevantes e síntese. A identificação dos artigos foi realizada na base de dados PUBMED www.ncbi.nlm.nih.gov/pubmed/. Foi concluído que é necessário aliar o uso de novas tecnologias como o RNAi com as ferramentas já utilizadas no manejo integrado de pragas para uma maior efetividade do controle de pulgão e mosca-branca, contudo, o contínuo estudo e aplicação de novas tecnologias moleculares na investigação de interações vírus-vetor fornecerá maior ajuda no controle das doenças virais de plantas disseminadas por pulgão e mosca-branca no futuro.
\end{abstract}

Palavras-chave: Controle de insetos. Interação molecular vírus-vetor. Manejo integrado de pragas. RNAi.

\section{Virus/vector interaction for aphids (Hemiptera: Aphididae) and whitefly (Hemiptera: Aleyrodidae)}

Abstract

\footnotetext{
${ }^{1}$ Universidade Federal de Uberlândia, Uberlândia - MG, Brasil https://orcid.org/0000-0001-8162-9174

${ }^{2}$ Universidade Estadual de Montes Claros, Montes Claros - MG, Brasil https://orcid.org/0000-0002-4605-6160

${ }^{3}$ Universidade Estadual de Goiás, Pires do Rio - GO, Brasil

https://orcid.org/0000-0003-2558-8691

${ }^{4}$ Universidade Estadual de Montes Claros, Montes Claros - MG, Brasil

https://orcid.org/0000-0002-0512-1616

${ }^{5}$ Universidade Federal de Uberlândia, Uberlândia - MG, Brasil

https://orcid.org/0000-0003-0087-7198

${ }^{6}$ Universidade Estadual de Montes Claros, Montes Claros - MG, Brasil https://orcid.org/0000-0001-8558-4196
}

*Autor para correspondência: ericsson_aerc@yahoo.com.br

Recebido para publicação em 01 de setembro de 2019. Aceito para publicação em 09 de setembro de 2019 e-ISSN: 2447-6218 / ISSN: 2447-6218 / (C) 2009, Universidade Federal de Minas Gerais, Todos os direitos reservados. 
Impact caused by aphids and whiteflies has grown considerably in the last decades, due to the increase in population outbreaks of of these virus-transmitting pests in a variety of economically important crops. The acquisition and transmission of most phytopathogenic viruses by a vector insect is the central point of the cycle of an infection. Plant viruses can interact with their insect hosts in a variety of ways, in some cases even virus replication can occur in insect cells. Virus interaction with your host/vector insects requires specific molecular interactions between virus and host, commonly via proteins, however, which vector components are involved and how they work to facilitate transmission is not well understood. The focus of the present work was to perform a systematic review on the basic virus/vector relationships in aphids and whiteflies; to show the practices currently used in integrated pest management for aphids and whiteflies and to report how insect vector interactions are opening new doors for the control of insect plant virus vectors using new genetic and computational technologies. The systematic review methodology was used, the work was conducted in stages that involved the development of the review protocol with the research questions, the search strategy, the identification of the inclusion and exclusion criteria, the search in the databases, previously defined, critical evaluation, extraction of relevant data and synthesis. Identification of articles was realized in the PUBMED database www.ncbi.nlm.nih.gov/pubmed/. We concluded it is required to combine the use of new technologies such as RNAi with the tools already used in integrated pest management for greater effectiveness of aphid and whitefly control, however, the continued study and application of new molecular technologies in investigating virus-vector interactions will provide further assistance in the control of plant diseases spread by aphid and whitefly in the future.

Keywords: Insect control. Molecular interaction virus/vector. Integrated pest management. RNAi.

\section{Introdução}

Os fitovírus estão entre os mais importantes agentes fitopatogênicos apresentando características peculiares que os distinguem de características observadas em fungos e bactérias. Os vírus são parasitas intracelulares obrigatórios e apresentam uma estrutura simples formada por um pequeno fragmento de ácido nucléico (DNA ou RNA) envolto por uma capa protéica, estas estruturas estão envolvidas na regulação, amplificação e tradução do gênoma viral, movimento célula-a-célula e sistêmico no hospedeiro, produção de proteínas não estruturais envolvidas na transmissão por vetores, fator de transmissão via sementes, inibidor da resposta de defesa da planta e interações com fatores do hospedeiro na indução de sintomas. A interação estabelecida entre a maioria dos fitovírus e seus vetores, principalmente afídeos e moscas-branca, considerados os principais vetores de vírus, são de extrema importância no estabelecimento da doença nos seus hospedeiros, pois dentre os patógenos de plantas, os vírus são dependentes dos seus vetores devido a não poder ser disseminados de forma livre no meio ambiente (Hill eWhitham, 2014; Ivanov et al., 2014; Revers e García, 2015).

Existem mais de 2000 espécies de vírus e os que afetam plantas incluem vírus de pelo menos 21 famílias muitos dos quais causam doenças importantes em várias culturas economicamente importantes para os humanos. Além disso, muitos vírus de plantas foram encontrados associados a plantas não cultivadas e novos vírus de plantas estão sendo descobertos graças aos avanços da tecnologia (bioinformática). As doenças virais representam $47 \%$ das novas doenças emergentes que afetam as plantas, tornando os vírus que infectam plantas muito bem sucedidos. Considera-se como vetor o organismo que durante seu processo natural de alimentação demonstre a capacidade de adquirir o vírus em uma planta infectada e durante a alimentação subsequente possa de inoculá-lo em uma planta sadia. (Silva et al., 2010). Para sobrevi- ver, os vírus que infectam as plantas devem ter um meio eficiente de passar de um hospedeiro para outro. Para isso, a grande maioria dos vírus de plantas utiliza vetores específicos para garantir sua capacidade de se deslocar de uma planta para outra garantindo sua sobrevivência, para isso os vírus de plantas codificam proteínas específicas que facilitam esse processo (Anderson et al., 2004; Moreno et al., 2019).

As interações vetor-vírus podem ser influenciadas por uma variedade de fatores dos vírus, plantas e insetos (Mauck et al., 2018; Mauck et al., 2014). Também influenciam as interações: proteínas virais (Casteel et al., 2015), perfis voláteis de plantas e status de nutrientes (Mauck et al., 2010), indução de defesa nas plantas (Zhang et al., 2012) e resposta dos insetos a estímulos visuais, sensoriais e olfativos (Eigenbrode et al., 2002; Srinivasan et al., 2009; Mauck et al., 2010). Além do mais, dicas visuais provenientes de plantas infectadas por vírus, como amarelecimento, parecem tornar as plantas mais aparentes para seus vetores (Döring e Chittka, 2007). Uma vez que os vetores estão estabelecidos, a qualidade da planta hospedeira pode desempenhar um papel crítico na determinação dos efeitos a longo prazo do vírus nos vetores (Mauck et al., 2018).

Os efeitos dos vírus na qualidade geral das plantas hospedeiras depende do modo de transmissão, embora isso pareça ser verdade com vírus persistentes, as interações vetor-vírus não-persistentes não indica um padrão genérico, estudos sobre vírus não-persistentes relataram resultados favoráveis, neutros e efeitos prejudiciais sobre a qualidade da planta hospedeira (Mauck et al., 2012). A maioria das manipulações de plantas e vetores causadas por vírus é provavelmente mediada por determinantes bioquímicos como aminoácidos livres, carboidratos solúveis e compostos sinalizadores de defesa. Aminoácidos livres e carboidratos solúveis, especialmente parecem ser 
Interação vírus/vetor para pulgões (Hemiptera: Aphididae) e mosca-branca (Hemiptera: Aleyrodidae)

os principais contribuintes para a qualidade da planta hospedeira para vetores (Eigenbrode et al., 2017; Mauck et al., 2018). Como exemplo, essas mudanças bioquímicas na planta podem influenciar a biologia do pulgão de maneira positiva (Castle e Berger, 1993) e negativa (Eigenbrode et al., 2017).

Existem trabalhos mostrando as interações das proteínas virais com as proteínas do vetor hospedeiro (Hogenhout et al., 2008; NG e Falk, 2006), no entanto, quais componentes do vetor estão envolvidos e como eles funcionam para facilitar a transmissão é continuamente estudado e ainda não está bem entendido. No presente estudo, será feito uma caracterização das relações básicas entre vírus-vetor e avaliação do uso de novas tecnologias moleculares aliadas com práticas já conhecidas no manejo integrado de pragas para controle da disseminação de vírus de plantas por pulgões e mosca-branca.

O objetivo deste estudo foi realizar uma revisão sistemática sobre as relações básicas de interação vírus/ vetor em afídeos e mosca-branca, caracterizar as modalidades de transmissão dos vírus por afídeos e mosca branca, identificar as práticas utilizadas atualmente no manejo integrado de pragas para afídeos e mosca branca e relatar como as interações vetoriais de inseto estão abrindo portas para o controle de insetos vetores de vírus plantas com o uso de novas tecnologias genéticas e computacionais.

Seguindo a metodologia de revisão sistemática, o trabalho foi conduzido em etapas que envolveram o desenvolvimento do protocolo de revisão com as questões da pesquisa, a estratégia de busca, a identificação dos critérios de inclusão e exclusão, a busca nas bases de dados previamente definidas, avaliação crítica, extração dos dados relevantes e síntese. A identificação dos artigos foi realizada na base de dados PUBMED www.ncbi.nlm. nih.gov/pubmed/.

\section{Classificação das relações dos vírus e seus insetos vetores}

A descrição da relação vírus/vetor foi relatada primeiramente no sistema de classificação adotado na fitopatologia, baseado nas relações dos vírus com os afídeos, esta relação foi denominada como persistente e não persistente, após avanços nos estudos foi observado que alguns vírus eram retidos pelos seus vetores por um determinado período de tempo, sendo classificado como transmissão semi-persistente. Outra modalidade relatada de transmissão em que os vírus, adquiridos via canal estiletar, circulava por meio da hemolinfa até atingir as glândulas salivares do inseto sendo denominada de relação circulativa. Foi relatado que alguns vírus, além da capacidade circulativa, demonstravam a habilidade de se replicar no vetor denominando este tipo de relação de circulativa-propagativa. Atualmente, após revisão das relações de transmissão, adota-se a classificação que as dividem em: transmissão não-circulativa (não-persistente e semipersistente) e transmissão circulativa (propagativa e não propagativa) (NG e Perry, 2004; Miller e Foottit, 2017).

\section{Modalidades de transmissão dos vírus}

As modalidades de transmissão foram denominadas baseando-se em estudos efetuados com insetos pertencentes à ordem Hemiptera. Os insetos vetores de vírus de plantas mais bem caracterizados são pulgões e moscas-brancas. Este tem sua importância como vetores de diversos vírus e por apresentar bem estabelecidas as etapas de aquisição, latência, inoculação e retenção do vírus (Bragard et al., 2013).

\section{Transmissão não-circulativa}

A maioria dos vírus de plantas transmitidos por pulgões segue uma estratégia não-circulativa. As características básicas dos vírus não-circulativos incluem a capacidade de ser adquirido em um curto período de tempo (segundos a minutos) e ser transmitido em intervalo de tempo sem período latente. Baseado nos períodos de inoculação e aquisição e o local de retenção no vetor é possível distinguir duas categorias de vírus não-circulativos: não-persistente e semi-persistente. A transmissão não-persistente tem como características estar associada ao estilete do vetor, sendo os vírus adquiridos retidos por minutos ou poucas horas; os vírus serem facilmente perdidos durante as provas de alimentação e apresentarem baixa especificidade (vírus-vetor). A transmissão semi-persistente compartilha algumas características com as observadas na transmissão não-persistente, porém, a associação biológica do vírus e vetor localiza-se na região proximal anterior do sistema digestivo dos insetos, onde os vírus podem ser retidos por horas ou dias (Fereres et al., 2015; Moreno et al., 2019)

A associação de vírus não-persistentes com seus vetores pode ser transitória e/ou específica ao contexto, resultando em variáveis efeitos que vão desde o aumento da atração a plantas infectadas e a rápida dispersão até a maior aptidão. A infecção na planta por Cucumber mosaic virus (CMV), aumenta a atração de afídeos para plantas infectadas de cucurbitáceas e encoraja a rápida dispersão do pulgão após a aquisição do vírus através do aumento de emissões de voláteis na planta hospedeira (Mauck et al., 2014; Eigenbrode et al., 2017; Mauck et al., 2018;). Por outro lado, outros vírus não-persistentes transmitidos por pulgões, incluindo Potato virus Y (PVY), Turnip mosaic virus (TuMV) e Zucchini mosaic virus (ZYMV), ocorre o aumento da qualidade nutricional da planta hospedeira para os afídeos (Blua e Perring, 1994; Boquel et al., 2011; Casteel et al., 2014).

Para potyvírus, sabe-se que a interação entre a proteína do capsídeo $(\mathrm{CP})$ e a receptor na cutícula da ponta do estilete do pulgão é mediado por uma proteína componente auxiliar (HC-pro). Na CP, o capsídeo do vírus interage diretamente na adesão da partícula 
de Oliveira, A. M. E. et al.

junto à cutícula do estilete do afídeo. Para se entender essas interações, se tem a necessidade da utilização das estratégias moleculares justificando-se diante de outros fatores particulares observados na interação vírus/vetor quando se trata da transmissão não persistente. $O$ primeiro fator a ser considerado é o volume de extrato de planta transferido durante a seleção da hospedeira que pode variar de acordo com a capacidade do inseto. Assim, para que ocorra a aquisição e transmissão do vírus, quanto maior a população da espécie de afídeos, maior será sua capacidade de transmissão (Syller, 2006; Whitfield et al., 2015).

O Cauliflower mosaic virus (CaMV), pertencente a família Caulimoviridae, pode ser adquirido por sondagem por pulgões, punção transitória das células da epiderme, mesófilo, parênquima de tecidos foliares infectados e também quando os pulgões se alimentam de tecidos do floema. Uma interação tritrófica elaborada determina a transmissão do CaMV pelos afídeos, ou seja, a transmissão CaMV pelo pulgão requer interações entre três proteínas codificadas por CaMV, uma das quais, P2 que interage com o estilete do afídeo, outra proteína P3 codificada por CaMV é ancorada dentro do invólucro do capsídeo do vírion e a HC-Pro (Hoh et al., 2010).

Embora a transmissão não-circulativa não persistente de vírus de plantas seja encontrada apenas entre vírus transmitidos por vetores pulgões, vários vírus transmitidos por pulgões, mosca-branca e cigarrinha mostram uma relação de transmissão semi-persistente e não circulativa. Os vírus que apresentam esse tipo de relação de transmissão são retidos por vetores virulíferos por períodos de tempo mais longos do que os vírus transmitidos de maneira não-persistente e são perdidos por vetores virulíferos durante a muda. Esta última propriedade suporta a hipótese de que esses vírus não são internalizados dentro das vísceras dos insetos, mas são provavelmente retidos em áreas delimitadas por quitina que são perdidas durante a muda dos insetos vetores. Descobertas recentes com o Lettuce infectious yellows virus (LIYV, gênero Crinivirus, família Closteroviridae) transmitido por Bemisia tabaci identificaram não apenas a proteína codificada por LIYV determinando sua transmissão por B. tabaci, mas também onde na mosca-branca os vírions de LIYV são retidos (NG e Falk, 2006; Stewart et al., 2010; Chen et al., 2011).

\section{Transmissão circulativa não-propagativa}

Este modo de transmissão é caracterizado pela internalização do vírus dentro do inseto sem replicação ou mesmo transcrição do genoma viral. Depois de se alimentar de uma planta infectada, o vírus é ingerido pelo vetor, juntamente com a seiva. $\mathrm{O}$ vírus é então transportado através do intestino do inseto e liberado na hemolinfa antes de penetrar nas glândulas salivares, de onde é injetado pela saliva durante a alimentação em uma nova planta. Apesar de não se replicar, o vírus pode permanecer infeccioso no vetor por vários dias e até mesmo durante a vida útil do vetor em alguns casos (Sicard et al., 2015).

Os luteovírus (família: Luteoviridae), são vírus que contém em seu material genético RNA de fita simples, senso positivo e são transmitidos por vetores afídeos de maneira não-propagativa e circulatória. A via de disseminação e as interações associadas entre vírus/vetor são bem caracterizadas pela transmissão de luteovírus pelos vetores afídeos. Os luteovírus são adquiridos quando os afídeos se alimentam dos tecidos do floema das plantas infectadas, estes vírus são relativamente pequenos e simples, apresentando vírions icosaédricos que entram no corpo do inseto através do canal alimentar. Os vírions interagem com as moléculas na superfície das células epiteliais do intestino do inseto, entram em uma forma endocítica mediada por receptor e atravessam a camada de células epiteliais sem a remoção do revestimento do vírus. Subsequentemente, os vírions estabelecem no espaço entre o plasma plasmático basal e a lâmina basal através da via exocítica. Estes processos de transporte endo e exocíticos dos vírions é denominado transcitose. O mecanismo para o movimento do vírus através da lâmina basal ainda não é bem compreendido. Os vírions atingem a hemocele, que é a cavidade situada no corpo dos artrópodes, caracterizada pela presença de hemolinfa, onde se sugere que endossimbiontes bacterianos aumentem a eficiência da transmissão vetorial. Uma vez que os vírions entram no hemocele, eles circulam e penetram nas glândulas salivares acessórias para serem inoculadas. Para a maioria dos luteovírus caracterizados, o intestino não é uma barreira importante para a entrada dos vírus e é comum que vírus também entrem na hemocele de pulgões não vetores. Como esses vírus não se replicam no vetor, se tem um maior acúmulo do vírus nas plantas e períodos mais longos de alimentação aumentam a quantidade de vírus abrigado no pulgão aumentando a eficiência da transmissão (Gray e Gildow, 2003; Gray et al., 2014).

Assim como a família Potyviridae, os gêneros do vírus da família Geminiviridae são transmitidos por vetores de uma maneira específica do gênero do vírus. As moscas brancas transmitem os vírus do gênero Begomovirus, por exemplo Tomato yellow leaf curl virus (TYLCV). Como nos luteovírus, a rota dos begomovírus começa com o inseto alimentando-se da seiva do floema de plantas infectadas, os vírions são ingeridos e viajam através do canal alimentar. Os vírions atravessam o intestino na região do intestino médio e a maioria se acumula na região da câmara filtro. Na maioria dos casos, os begomovírus não se replicam em seus vetores e os vírions se movem através do intestino por transcitose que é um processo celular (combinação de endocitose e exocitose), muito semelhante aos luteovírus. Os vírions são liberados nas células intestinais, viajam através da hemocele do inseto e alcançam as glândulas salivares primárias, movendo-se através da glândula salivar e de diferentes barreiras físicas para a transmissão ocorrer. Como nos luteovírus, supõe-se que endossimbiontes bacterianos residentes em 
Interação vírus/vetor para pulgões (Hemiptera: Aphididae) e mosca-branca (Hemiptera: Aleyrodidae)

bacteriócitos, células especializadas na hemocele, possam desempenhar um papel na transmissão do vírus (Cicero e Brown, 2011; Gray et al., 2014; Wang et al., 2014).

\section{Transmissão circulativa-propagativa}

A transmissão circulativa-propagativa tem como diferencial a multiplicação do vírus no vetor apresentando maior período de latência quando comparado com os vírus de transmissão não-propagativa. Os vírus da família Rhabdoviridae, que são vírus que contém em seu material genético RNA de fita simples, senso negativo, podem ser transmitidos de forma persistente, circulativa-propagativa por pulgões, gafanhotos ou cigarrinhas. As células epiteliais do intestino médio dos insetos hemípteros são revestidas com tecidos musculares que controlam o movimento do intestino anterior e do intestino médio e estão ligadas ao tecido nervoso através de uma rede de gânglios, os rabdovírus que infectam plantas adquiridos durante a alimentação da seiva podem usar essas conexões como uma via alternativa às glândulas salivares (Dietzgen et al., 2016).

Um dos patógenos mais importantes na cultura do tomate podendo gerar perdas de até $100 \%$ de produtividade é o Tomato yellow leaf curl virus (TYLCV) (Gênero: Begomovirus, Família: Geminiviridae). O TYLCV é transmitido exclusivamente pela mosca-branca Bemisia tabaci que adquiri o vírus do floema da planta como vírions intactos que passando ao longo do canal de alimentação canal no estilete inseto com outros até chegar ao esôfago. Os vírions são transportados através das células epiteliais do citoplasma em vesículas que se fundem com a membrana do plasma basal, liberando partículas entre a membrana e a lâmina basal, uma vez que eles cruzam as células do intestino médio, os vírions ficam temporariamente na hemocele e em seguida, entram no duto salivar de onde são transmitidos para as plantas durante a alimentação. Este processo demora um mínimo de $8 \mathrm{~h}$ (período latente) considerando o momento em que o vírus é adquirido de plantas de tomate infectadas até ser efetivamente transmitido para outras plantas (Moriones e Navas-Castillo, 2000; Pakkianathan et al., 2015; Ghanim et al., 2001)

\section{Relação vírus/vetor em pulgão e mosca-branca}

A morfologia do aparelho bucal (sugador), hábitos alimentares (fitófagos e polífagos) e biologia (partenogênese e gerações sucessivas em curto período de tempo) são características presentes na maioria das espécies transmissoras aumentando a eficiência da relação vírus/ inseto vetor. A característica morfológica mais importante nos hemípteros, independentemente da família envolvida na transmissão é a de apresentarem aparelho bucal notavelmente semelhante, constituído basicamente por dois pares de estiletes (mandibulares e maxilares) em forma de agulha, de um lábio e um labro. Esta característica confere um hábito uniforme de alimentação que consiste na introdução dos estiletes no tecido, culminando na ingestão e e gestão do conteúdo celular ou da seiva do hospedeiro (Miller e Foottit, 2017).

Os afídeos tem sua importância na transmissão e disseminação dos vírus, pois relacionam-se diretamente à sua habilidade excepcional de interação com plantas hospedeiras e sua forma de reprodução. Dentre as transmissões dos vírus realizada por afídeos, a realizada de forma não persistente é a que conduz a maiores prejuízos às culturas de importância econômica. A ausência de especificidade entre as espécies de vírus e afídeos e o fato da aquisição e inoculação dos vírus ocorrerem durante picadas de prova, não havendo, portanto necessidade de colonização da planta pelo afídeo, para que ocorra a transmissão, constituem as principais características a serem consideradas. Desta forma, o controle químico da população de afídeos não é um meio eficiente para deter a disseminação do vírus no campo. Assim, os afídeos são considerados os insetos mais importantes dentre os vetores, devido à sua característica de transmitir, de forma não persistente, diferentes gêneros de vírus que filogeneticamente caracterizam-se por formar um grupo polifilético, ou seja, constituído por descendentes de mais de uma espécie ancestral (Moran, 1992; Pirone e Kerry, 2002).

O pulgão-verde, Myzus persicae (Hemiptera: Aphididae), é um inseto polífago de grande importância econômica correspondente aos danos diretos ocasionados pela contínua sucção de seiva provocando nanismo na plantas, também levando a parte da folha atacada a crescer menos que a parte não atacada, além das folhas ficarem muito deformadas (Kasprowicz et al., 2008). O Papaya ringspot virus (PRSV), um potyvírus de RNA de sentido positivo de cadeia simples é principalmente agrupado em duas estirpes, o PRSV-P que afeta a cultura do mamão e cucurbitáceas e o PRSV-W que afeta exclusivamente cucurbitáceas. A estirpe PRSV-W causa perdas de produção em cucurbitáceas em todo o mundo. O PRSV-W é transmitido por várias espécies de afídeos de uma forma não persistente. O afídeo do melão (Aphis gossypii Glover) é o vetor mais eficiente desse vírus e é uma praga economicamente importante de cucurbitáceas em todo o mundo (Kalleshwaraswamy e Kumar, 2008). Um trabalho recente avaliou se os efeitos da aptidão nos pulgões são modulados através de mudanças no perfil nutricional na planta hospedeira de PRSV na abóbora (Cucurbita pepo L.). Foram utilizados insetos vetores (Aphis gossypii Glover) e não-vetores como a mosca-branca prateada (Bemisia tabaci Gennadius). O desempenho global de A. gossypii foi substancialmente mais alto nas plantas infectadas com PRSV. Plantas infectadas com PRSV aumentaram as concentrações de aminoácidos essenciais livres: treonina, arginina e lisina; aminoácidos não-essenciais: glicina e homocisteína; e também carboidratos solúveis: galactose, rafinose e celobiose. No geral, a presença de PRSV no hospedeiro estimulou a alimentação a longo prazo e melhorou a aptidão de $A$. gossypii através do aumento de nutrientes na planta hospedeira, fato relacionado 
de Oliveira, A. M. E. et al.

como aptidão positiva mediada pelo vírus (Gadhave et al., 2019).

Aphis spiraecola Patch é um pulgão polífago sendo uma das principais pragas da cultura da maçã e também é considerada como uma das principais pragas dos pomares cítricos no mundo. A diversidade de sua gama de hospedeiros inclui plantas pertencentes a 278 espécies. Plantas pertencentes às seguintes famílias são altamente infestadas: Asteraceae, Cucurbitaceae, Fabaceae, Lamiaceae, Malvaceae, Polygonaceae, Rosaceae, Rutaceaee Solanaceae. Aphis spiraecola é um pulgão pequeno, de corpo mole, em forma de pêra, medindo cerca de 1,8-2,30 $\mathrm{mm}$ de comprimento com 1,28-1,2 mm de largura e de cor verde amarelado ou cor verde-maçã, tem a cabeça marrom e cauda marrom escuro a preto. Tanto as ninfas quanto os adultos de Aphis spiraecola alimentam das plantas sugando a seiva das plantas hospedeiras, principalmente a seiva das folhas, caules e inflorescência e das gemas em desenvolvimento. Devido à alta população de Aphis spiraecola toda a planta fica desvitalizada, as folhas adquirem aparência encaracolada e os botões não convertem em flores (Gupta, 2012; Singh e Singh, 2016). São conhecidos 17 vírus de plantas que são transmitidos por Aphis spiraecola, sendo os mais importantes: Papaya ringspot virus (PRSV) (Gadhave et al., 2019) e Plum pox virus (PPV) (Glasa et al., 2007; Sheveleva et al., 2018).

Dentre as espécies de fitovírus que causam grandes perdas na produção de alface, a mais importante e que justifica a adoção de medidas de controle é o Lettuce mosaic virus (LMV), que são vírus de RNA senso positivo, fita simples, pertencente ao gênero Potyvirus, família Potyviridae. Os fatores que contribuem para o desenvolvimento e estabelecimento do LMV se encontram principalmente na sua característica de infectar uma grande variedade de hospedeiros, infecção em sementes e também por poder ser disseminado no campo por um grande número de espécies de afídeos de maneira não-circulativa. O LMV em relação a transmissão por sementes, é um exemplo clássico na epidemiologia de vírus devido a tramitação de sementes de alface entre países e continentes, principalmente ocorrida durante a colonização das Américas e também pela importação de novas variedades, constituindo assim, a principal fonte de inóculo primário para epidemias dessa virose. Com isso, os afídeos associam diversas características, conferindo grande importância econômica, devido ao seu alto poder de reprodução, sua habilidade de dispersão e especialmente por sua forma de alimentação que causa danos diretos devido aos ataques a seus hospedeiros traduzindo em prejuízos na floração e na frutificação da planta, o dano indireto é a de transmitir diversas espécies de vírus. Alguns exemplos de espécies de afídeos que transmitem LMV pertencentes aos gêneros Aulacorthum, Acyrthosiphon, Aphis, Hyperomyzus, Myzuse Nasonovia (Krause-Sakate et al., 2004; Gibbs et al., 2008).

Os afídeos são capazes de se desenvolver rapidamente num curto período de tempo, quando as condições ambientais forem favoráveis para sua multiplicação, formando grandes colônias de insetos ápteros, alados e ninfas. As condições climáticas podem exercer grande influência no desenvolvimento dos afídeos, sendo que em baixas temperaturas, o período de desenvolvimento dos afídeos é retardado, bem como sua multiplicação; o contrário ocorre quando em temperaturas mais altas. Outro fator relevante é a ocorrência de chuvas intensas e prolongadas que limitam a ocorrência de grandes populações de afídeos. Uma das formas de controles de pulgões é o controle biológico que consiste na eliminação do inseto por inimigos naturais fazendo uma regulação do número de insetos. O controle biológico é uma eficaz ferramenta para ser utilizada no controle de afídeos principalmente em cereais de inverno. O controle dos afídeos por meio do parasitismo é responsável pela redução acentuada nas populações de afídeos. O monitoramento da população de afídeos também é utilizado em diversas culturas de plantas, com este monitoramento, é possível criar modelos de previsão para tomada de decisão de manejo destes afídeos. Contudo, o controle do pulgão é feito principalmente por aplicações de inseticidas sintéticos, porém seu uso indiscriminado pode causar problemas de natureza econômica, ecológica e ambiental devido à presença de resíduos nos alimentos, efeitos prejudiciais sobre os inimigos naturais e seleção de populações de insetos resistentes (Zuñiga e Guttierez, 2002; Costa et al., 2014).

Os adultos de mosca-branca são diminutos, ou seja, os machos menores e menos abundantes que as fêmeas, sendo insetos com cabeça opistognata aparentemente com o rostro separado da cabeça. Exibem o dorso amarelo-pálido e as asas membranosas e brancas com venação reduzida, medindo de $1 \mathrm{~mm}$ a $2 \mathrm{~mm}$ de comprimento e $0,36 \mathrm{~mm}$ a $0,51 \mathrm{~mm}$ de largura, seus olhos são vermelhos, compostos e divididos em duas partes por uma projeção cuticular e as antenas são curtas. Estes insetos tem preferência pela face abaxial das folhas para sua alimentação e oviposição. Os ovos são periformes, de coloração branco-amareladas nos primeiros dias e marrons próximos à eclosão podendo ser arranjados isoladamente ou em grupos de forma irregular ou em semicírculos. Os ovos são dotados de pedicelo, que é uma extensão do córion, que fica inserido nas células da epiderme da folha, não atingindo as células do parênquima. Através do pedicelo ocorre absorção de água e soluto das folhas que são essenciais ao desenvolvimento do ovo. Em média, uma fêmea produz 100 ovos podendo ultrapassar 300 ovos em algumas regiões. As ninfas eclodem em média em 7 dias, dependo da temperatura ambiente, estas são translúcidas apresentando coloração amarela ou amarela-pálida, sendo a parte dorsal lisa, plana ou levemente convexa. A fase imatura das moscas brancas ocorre em quatro ínstares, sendo apenas o primeiro móvel e os demais ínstares permanecem imóveis, porém sempre se alimentado. Contudo, no quarto ínstar, a ninfa se alimenta apenas por um curto período e depois cessa sua alimentação, esta fase é descrita como estádio pupal, compreendendo o período de não alimentação 
Interação vírus/vetor para pulgões (Hemiptera: Aphididae) e mosca-branca (Hemiptera: Aleyrodidae)

da ninfa até a emergência do adulto. A mosca-branca é um inseto multivoltino, podendo apresentar muitas gerações por ano, os principais fatores ambientais que afetam o número de gerações da mosca-branca são a temperatura e a disponibilidade de alimento. Bemisia tabaci é considerada um complexo de pelo menos 40 espécies crípticas que apresentam diversidade genética e biológica, as espécies do complexo Bemisia tabaci são morfologicamente indistinguíveis, mas diferem entre si em diversos aspectos incluindo a gama de hospedeiros, a capacidade em causar desordens fisiológicas nas plantas, atração a inimigos naturais, resposta à pesticidas e diferentes capacidades na transmissão de vírus de plantas (Gerling et al., 1986; Buckner et al., 2002; De Barro et al., 2010; Stansly e Naranjo, 2010).

A mosca-branca, Bemisia tabaci Gennadius (Aleyrodidae: Hemiptera) é uma das principais pragas agrícolas gerando prejuízos em diversas culturas transmitindo doenças virais, principalmente na África, onde a cultura da mandioca atualmente tem a maior produção sendo a cultura mais resistente às mudanças climáticas, doenças virais como o African cassava mosaic virus transmitidas pela mosca-branca causam perdas de 1 bilhão de dólares anualmente na África. Além disso, a mosca-branca está disseminada em todas as regiões do globo, exceto no ártico, e pode atacar mais de 1000 espécies de vegetais (Abd-Rabou e Simmons, 2012; Jacobson et al., 2018).

Os danos causados pela mosca-branca podem ser diretos ou indiretos. Os danos diretos se relacionam à sucção de seiva do floema e por injetar toxinas que provocam desordens funcionais na planta hospedeira, implicando em perdas na qualidade e na produtividade em várias culturas agrícolas. Os danos indiretos são relacionados à produção de "honeydew", que serve como substrato para o crescimento do fungo de cor preta denominado de fumagina (Capnodium sp.), cobrindo a superfície foliar impedindo a absorção de luz pelas folhas, reduzindo a taxa fotossintética das plantas. Contudo, o principal dano indireto da mosca-branca são os vírus por ela transmitidos (Rojas et al., 2018).

A mosca-branca é descrita como vetor de mais de 300 viroses onde cerca de $90 \%$, pertencem ao gênero Begomovirus. Destacam entre os begomovírus transmitidos por mosca-branca, o Bean golden mosaic virus, Tomato golden mosaic virus e o African cassava mosaic virus. Ambas as viroses, podem causar perdas de até 100\% da produção nessas culturas, principalmente, se a infecção ocorrer na sua fase inicial. O manejo e controle de doenças virais em mandioca dependem basicamente de cultivares tolerantes. Com isso, novos genes alvos para a resistência de vírus de plantas são essenciais para o desenvolvimento de cultivares de mandioca resistente a vírus por melhoramento convencional ou engenharia genética. Sequências completas de genomas de cloroplastos são interessantes para entender as relações filogenéticas entre diferentes grupos taxonômicos relacionados e para aperfeiçoar o conhecimento sobre evolução das espécies.
O cloroplasto é um alvo comum para a replicação dos vírus de plantas, e reciprocamente, os componentes do cloroplasto também tem um papel ativo na defesa contra vírus de plantas fazendo desta organela uma potencial fonte para a descoberta de novos genes contra patógenos invasores como os vírus de plantas. Com isso, muitos fatores do cloroplasto têm sido identificados interagindo com componentes virais, esses fatores estão envolvidos na replicação viral, movimento, sintomas ou defesa da planta, sugerindo que os vírus evoluem para interagir com ocloroplasto (Navas-Castillo et al., 2011; Zabala et al., 2015; Daniell et al., 2016; Zhao et al., 2016; Jacobson et al., 2018; Rojas et al., 2018).

O Bean golden mosaic virus (BGMV) é o principal vírus descrito em feijoeiro comum e é transmitido pela mosca-branca. O BGMV provoca redução do crescimento da planta, deformação, amarelecimento das folhas, deformação e redução do número de vagens, redução do número e peso dos grãos. Em campo, os sintomas podem ser observados a partir de 14 dias da emergência do feijoeiro e quanto mais cedo ocorrer à infecção, maiores serão os prejuízos à cultura. Epidemias da doença variaram ao longo das últimas décadas, mas com ocorrência frequente, principalmente em condições de veranicos e após o cultivo da soja (Faria et al., 2000; Inoue-Nagata et al., 2006).

O manejo de doenças virais mais comuns associadas a mosca-branca é baseado no controle deste inseto. A mosca-branca é controlada principalmente pelo método químico com o emprego de inseticidas sintéticos. Surtos populacionais da mosca-branca são relatados em várias regiões do Brasil e sempre estão associados ao alto grau de polifagia da praga e a dificuldade de controle. Assim, o manejo deste inseto praga não deve ser realizado apenas na cultura principal, mas também deve envolver todo o sistema produtivo. Em locais onde são cultivadas espécies de plantas que servem como hospedeiros do vírus o ano todo de modo sucessivo proporcionado pelo uso da irrigação, os cuidados devem ser redobrados (Gilbertson et al., 2015; Quintela et al., 2016). A mosca-branca tem grande importância econômica na agricultura, devido ao seu difícil controle e grande variedade de hospedeiros. Existem muitas táticas de controle que podem ser integradas e avaliadas para reduzir os danos da praga e impedir grandes surtos populacionais. No campo, o agricultor basicamente tem feito o controle da mosca-branca com a aplicação de inseticidas e em muitos casos, não se baseiam na densidade populacional para este tipo de controle. As aplicações são realizadas em caráter preventivo e/ou curativo com inseticidas de amplo espectro e de baixa eficácia, o que tem incitado várias aplicações por cultivo resultando em resistência do inseto a muitos inseticidas. Por ser transmissor de vírus, os agricultores realizam a aplicação de inseticidas, porém, em culturas como algodão, soja e tomate se usa os níveis de controle para mosca-branca, entretanto, ao se relacionar a mosca-branca como transmissora de virose, em tomate ou feijão, apenas um inseto é capaz de disseminar a doença 
de Oliveira, A. M. E. et al.

(Palumbo et al., 2001; Gusmão et al., 2005; Naranjo et al., 2003; Erdogan et al., 2008; Gilbertson et al., 2015).

O manejo e o controle da mosca-branca nas últimas décadas tem sofrido mudanças principalmente devido ao aparecimento de resistência a muitos inseticidas. Com isso, existe a necessidade de associação de diferentes técnicas ou métodos de controle. No Brasil, os avanços no manejo da mosca-branca ocorreram devido ao controle legislativo e cultural, principalmente em tomate e feijão, culturas que registram grandes prejuízos causados por doenças virais (Palumbo et al., 2001; Nauen e Denholm, 2005; Inoue-Nagata et al., 2006).

Outros métodos de controle usados para a mosca-branca são: escolha de época de cultivo o que pode resultar na diminuição do uso de inseticidas. A eliminação imediata dos restos de cultura, plantio de mudas/sementes sadias e vigorosas, uso de barreiras vivas, controle de plantas daninhas, o uso de variedades resistentes a vírus. Outra ferramenta muito importante para o manejo da mosca-branca é o controle biológico, são exemplos de agentes naturais de controle da mosca-branca: os fungos, os predadores e os parasitoides. Os gêneros $A s$ chersonia, Verticillium (Lecanicillium), Beauvariae Isaria (Paecilomyces) são, comumente, associados à redução populacional de mosca-branca ao redor do mundo. Os predadores de Bemisia tabaci são importantes agentes de regulação populacional da mosca-branca, sendo insetos pertencentes às ordens Coleoptera, Diptera, Heteroptera, Hymenoptera, e Neuroptera, além de aranhas e ácaros (Ellsworth e Martinez-Carrillo, 2001; Faria e Wraight, 2001; Meekes et al., 2002; Oliveira et al., 2003; Cabanillas e Jones, 2009).

\section{Passos críticos em interações vírus-insetos como po- tenciais alvos de controle}

Os vetores de insetos desempenham um papel crucial na determinação do alcance de um hospedeiro na planta. A competência para a transmissão do vírus é determinada por componentes genéticos e interações moleculares específicas do vírus e vetor, e potencialmente componentes da planta hospedeira retirados durante a alimentação. O melhor conhecimento destas interações e mecanismos de transmissão serão essenciais para o desenvolvimento de medidas de controle mais efetivas no futuro. Estratégias atualmente disponíveis para interferir na transmissão do vírus por vetores incluem a resistência genética do hospedeiro ao vírus e/ou insetos, inseticidas e manejo integrado de pragas. As interações vírus-vetor podem variar dependendo do modo de transmissão do vírus que pode envolver as partes bucais de alimentação (estiletes), o intestino anterior (semi-persistente) ou a captação de vírus e circulação através do corpo do inseto (persistente) (Bragard et al., 2013; Dietzgen et al., 2016). Em outros insetos como mosquitos que transmitem Dengue, Zika, são utilizados métodos de controle fazendo uma relação micróbio/vírus/vetor, os micróbios invadem a população de mosquitos manipulando seu sistema re- produtivo, gerando mosquitos não-infectados (Bourtzis et al., 2014).

Nos últimos anos surgiu uma alternativa potencial e estratégia eficaz para o controle de pulgões e mosca-branca na agricultura. O RNA interferente (RNAi) é uma estratégia de silenciamento gênico pós-transcricional na qual o RNA de fita dupla (dsRNA), correspondente especificamente a um gene alvo é introduzido em um organismo alvo. O RNAi é uma ferramenta poderosa para resolver o problema dos agricultores com pragas sugadoras de seiva, pois esta ferramenta é altamente específica para o alvo. O mecanismo de silenciamento mediado por RNAi pode ser dividido em três passos. Primeiro, um dsRNA correspondente a um fragmento de um gene alvo, expresso ou introduzido no citoplasma da célula, que é digerida em pequenos RNAs de interferência dupla (siRNAs) pela ação de uma enzima RNase III chamada Dicer; segundo, os duplexes de siRNA são carregados no silenciamento induzido por RNA complexo (RISC) e um filamento conhecido como a cadeia-guia, é preferencialmente mantida enquanto a outra chamada de cadeia de passageiros, está marcado para degradação; terceiro, o RISC dirigido pela fita guia RNA, localiza o mRNAs do gene alvo complementar à cadeia guia, estes dois então se ligam um ao outro, levando à degradação do mRNA alvo e bloqueio da tradução de mRNA (Siomi e Siomi, 2009; Grover et al., 2019).

Pesquisas sobre RNAi mostram seu sucesso como uma estratégia potencial de controle de afídeos e mosca-branca, que pode ser altamente específica para espécies e favorável ao meio ambiente. Em pulgões o direcionamento de RNAi da proteína da bainha estrutural (SHP), um componente fundamental do processo de endurecimento da bainha por plantas transgênicas de cevada expressando shp-dsRNA inibiram fortemente o comportamento alimentar e reprodutivo de pulgões e afetaram negativamente sua sobrevivência (Abdellatef et al., 2015). Em moscas-brancas o sucesso do fornecimento de dsRNA através da via oral abriu possibilidades para o seu manejo através de RNAi mediada por plantas. Até o momento, vários genes foram alvejados em moscas brancas através de RNAi e esses ensaios demonstraram seu potencial para o manejo de moscas brancas em laboratório. O RNAi é cada vez mais utilizado para estudos genômicos funcionais de insetos vetores, incluindo gafanhotos, pulgões e tripes, e para atingir proteínas que interagem com proteínas virais. Essas análises são auxiliadas por recursos emergentes de genoma e transcriptoma de insetos incluindo os genomas do pulgão-da-ervilha (Acyrthosiphon pisum) e pulgão-verde-do-pêssego ( $M$. persicae). Análise de transcriptoma de vetores competentes na transmissão usando sequenciamento de RNA e RT-PCR tem sido usado para identificar a resposta de genes de defesa de insetos e identificar a expressão em tecidos relevantes como no intestino do inseto, glândula salivar e células do tecido nervoso (Chen et al., 2015; Dietzgen et al., 2016). 
Interação vírus/vetor para pulgões (Hemiptera: Aphididae) e mosca-branca (Hemiptera: Aleyrodidae)

Outra maneira pela qual o RNAi pode ser útil no manejo de mosca-branca é como uma ferramenta de pesquisa para investigar mecanismos de resistência a inseticidas. Os inseticidas são mais comumente usados em estufas, bem como em campos para controle de populações de mosca-branca, porém a rápida evolução da resistência em moscas-brancas tornou ineficaz a maioria dos tratamentos com inseticidas. O RNAi possui potencial para resolver este problema, visando enzimas de desintoxicação na mosca-branca e aumentando a sensibilidade da mosca-branca aos inseticidas. Com isso, a combinação do controle químico e RNAi podem desenvolver uma estratégia de controle mais estável. Além de direcionar genes essenciais para a sobrevivência, o RNAi também pode ser usado no manejo de afídeos e mosca-branca, visando genes relacionados a processos metabólicos ou comportamentais destes insetos, por exemplo, genes que desempenham um papel no comportamento de busca do hospedeiro, genes relacionados a endossimbiontes no intestino da mosca-branca e genes relacionados a mecanismos de resistência a inseticidas (Yu et al., 2016; Dângelo et al., 2018; Grover et al., 2019). Em um estudo se utilizou uma estratégia indireta para reduzir a carga de Bean golden mosaic virus (BGMV) na mosca-branca. Para isso foi desenvolvido um feijão geneticamente modificado (GM) que é imune ao BGMV pelo silenciamento do gene rep viral através de RNAi. Isso resultou em uma forte redução na quantidade de DNA de BGMV em moscas-brancas que se alimentam de plantas GM em comparação com insetos que se alimentam de plantas não-GM por um período de $4(-52 \%)$ e $8(-84 \%)$ dias (De Paula et al., 2015).

Apesar da tecnologia de RNAi ser atual, já foi relatado o primeiro caso de população de lagarta-da-raiz do milho (Diabrotica virgifera virgifera) resistente ao dsRNA. A caracterização da eficiência do RNAi nesta população mostrou que o mecanismo de resistência foi relacionado à captação celular de dsRNA e que os insetos resistentes a RNA foram resistentes a todos os dsRNAs apesar disto, o estudo relatou que esta população resistente a RNAi ainda era suscetível a toxinas $\mathrm{Bt}$, indicando que a agregação de tecnologias podem ser benéficas para evitar o rápido desenvolvimento de resistência nas populações (Khajuria et al., 2018).

\section{Considerações finais}

A aplicação de tecnologias moleculares na investigação de interações vírus-vetor fornecerá maior ajuda no controle das doenças virais no futuro. As interações proteína-proteína entre os vírus das plantas e seus insetos vetores são uma interface molecular essencial que determina a aquisição em plantas hospedeiras infectadas e a transmissão para outros hospedeiros. A aparente especificidade na transmissão destas interações em ambos os vírus vegetais persistentes e não-persistentes abre caminhos para a interferência e controle das populações vetoriais, bem como a transmissão do vírus. A crescente aplicação de tecnologias tem o potencial de contribuir significativamente para a identificação e validação de proteínas de insetos que interagem com os vírus. A tecnologia de RNAi que é uma alternativa promissora para a proteção de plantas contra a disseminação de doenças virais por pulgões e mosca-branca, porém, é importante aliar novas tecnologias com outras práticas de controle utilizadas no manejo integrado de pragas, pois as mutações genéticas em afídeos e mosca-branca podem desenvolver resistência nestes insetos tanto a inseticidas quanto inclusive a tecnologia de RNAi.

\section{Referências}

Abdellatef, E.; Wil, T.; Koch, A.; Imani, J.; Vilcinskas, A.; Kogel, K-H. 2015. Silencing the expression of the salivary sheath protein causes transgenerational feeding suppression in the aphid Sitobion avenae. Plant Biotechnology Journal, 13 (6): 849-857. doi: 10.1111/pbi.12322

Abd-Rabou, S.; Simmons, A. M. 2012. Survey of Reproductive Host Plants of Bemisia tabaci (Hemiptera: Aleyrodidae) in Egypt, Including New Host Records. Entomological News, 121 (5): 456-465. doi: 10.315/021.121.0507

Anderson, P. K. Cunningham, A. A.; Patel, N. G.; Morales, F. J.; Epstein, P. R.; Daszak, P. 2004. Emerging infectious diseases of plants: Pathogen pollution, climate change and agrotechnology drivers. Trends in Ecology and Evolution, 19 (10): 535-544. doi: 10.1016/j.tree.2004.07.021

Blua, M. J.; Perring, T. M.; 1994. Madore, M. A. Plant virus-induced changes in aphid population development and temporal fluctuations in plant nutrients. Journal of Chemical Ecology, 20 (3): 691-707. doi: 10.1007/BF02059607

Boquel, S.; Giordanengo, P.; Ameline, A. 2011. Divergent effects of PVYinfected potato plant on aphids. European Journal of Plant Pathology, 129 (4): 507-510. doi: 10.1007/s10658-010-9732-8
Bourtzis, K.; Dobson, S. L.; Xi, Z., Rasgon, J. L.; Calvitti, M.; Moreira, L. A.; Bossin, H. C.; Moretti, R.; Baton, L. A.; Hughes, G. L. 2014. Harnessing mosquito-Wolbachia symbiosis for vector and disease control. Acta tropica, 132: S150-S163. doi: 10.1016/j.actatropica.2013.11.004

Bragard, C.; Caciagli, P.; Lemaire, O.; Lopez-Moya, J.; MacFarlane, S.; Peters, D.; Susi, P; Torrance, L. 2013. Status and Prospects of Plant Virus Control Through Interference with Vector Transmission. Annual Review of Phytopathology, 51 (1): 177-201. doi: 10.1146/annurevphyto-082712-102346

Buckner, J. S. freeman, T. P.; Ruud, R. L.; Chu, C-c.; Henneberry, T. J. 2002. Characterization and functions of the whitefly egg pedicel. Archives of Insect Biochemistry and Physiology, 49 (1): 22-33. doi: 10.1002/arch.10006

Cabanillas, H. E.; Jones, W. A. 2009. Pathogenicity of Isaria sp. (Hypocreales: Clavicipitaceae) against the sweet potato whitefly B biotype, Bemisia tabaci (Hemiptera: Aleyrodidae). Crop Protection, 28 (4): 333-337. doi: 10.1016/j.cropro.2008.11.015

Casteel, C. L. Yang, C.; Nanduri, A. C.; De Jong, H. N.; Whitham, S. A.; Jander, G. 2014. The NIa-Pro protein of Turnip mosaic virus improves growth and reproduction of the aphid vector, Myzus persicae (green peach aphid). Plant Journal, 77 (4): 653-663. doi: 10.1111/tpj.12417 
Casteel, C. L. De Alwis, M,; Bak, A.; Dong, H.; Whitham, S. A.; Jander, G. 2015. Disruption of Ethylene Responses by Turnip mosaic virus Mediates Suppression of Plant Defense against the Green Peach Aphid Vector. Plant Physiology, 169: 209-215. doi: 10.1104/pp.15.00332

Castle, S. J.; Berger, P. H. 1993. Rates of growth and increase of Myzus persicae on virus-infected potatoes according to type of virus-vector relationship. Entomologia Experimentalis et Applicata, 69 (1): 51-60.

Chen, A. Y. S. Walker, G. P.; Carter, D.; Ng, J. C. K. 2011. A virus capsid component mediates virion retention and transmission by its insect vector. Proceedings of the National Academy of Sciences,108 (40): 16777-16782. doi: 10.1073/pnas.1109384108

Chen, Q. Wang, H.; Ren, T.; Xie, L.; Wei, T. 2015. Interaction between non-structural protein Pns10 of rice dwarf virus and cytoplasmic actin of leafhoppers is correlated with insect vector specificity. Journal of General Virology, 96 (4): 933-938. doi: 10.1099/jgv.0.000022

Cicero, J. M.; Brown, J. K. 2011. Functional Anatomy of Whitefly Organs Associated With Squash Leaf Curl Virus (Geminiviridae: Begomovirus) Transmission by the B Biotype of Bemisia tabaci (Hemiptera: Aleyrodidae). Annals of the Entomological Society of America, 104 (2): 261-279. doi: $10.1603 /$ AN10075

Dângelo, R. A. C. Michereff-Filho, M.; Campos, M. R.; da Silva, P. S.; Guedes, R. N. C. 2018. Insecticide resistance and control failure likelihood of the whitefly Bemisia tabaci (MEAM1; B biotype): a Neotropical scenario. Annals of Applied Biology, 172 (1): 88-99. doi: 10.1111/aab.12404

Daniell, H. Lin, C-S.; Yu, M.; Chang, W-J. 2016. Chloroplast genomes: Diversity, evolution, and applications in genetic engineering. Genome Biology, 17:1-29. doi: 10.1186/s13059-016-1004-2

De Barro, P. J.; liu, S-S.; Boykin, L. M.; Dinsdale, A. B. 2011. Bemisia tabaci : A Statement of Species Status. Annual Review of Entomology, 56 (1):1-19. doi: 10.1146/annurev-ento-112408-085504

De Paula, N. T.; De Faria, J. C.; Aragão, F. J. L. 2015. Reduction of viral load in whitefly (Bemisia tabaci Gen.) feeding on RNAi-mediated bean golden mosaic virus resistant transgenic bean plants. Virus Research, 210: 245-247. doi: 10.1016/j.virusres.2015.08.012

Dietzgen, R. G.; Mann, K. S.; Johnson, K. N. 2016. Plant virus-insect vector interactions: Current and potential future research directions. Viruses, 8 (11): 1-21. doi: 10.3390/v8110303

Döring, T. F; Chittka, L. 2007. Visual ecology of aphids-a critical review on the role of colours in host finding. Arthropod-Plant Interactions, 1 (1): 3-16. doi: 10.1007/s11829-006-9000-1

Eigenbrode, S. D.; Ding, H.; Shiel, P.; Berger, P. H. 2002. Volatiles from potato plants infected with potato leafroll virus attract and arrest the virus vector, Myzus persicae (Homoptera: Aphididae). Proceedings of the Royal Society B: Biological Sciences, 269 (1490):455-460. doi: 10.1098/rspb.2001.1909

Eigenbrode, S. D.; Bosque-Pérez, N. A.; Davis, T. S. 2017. Insect-Borne Plant Pathogens and Their Vectors: Ecology, Evolution, and Complex Interactions. Annual Review of Entomology, 63 (1): 169-191. doi: 10.1146/annurev-ento-020117- 043119

Ellsworth, P. C.; Martinez-Carrillo, J. L. 2001. IPM for Bemisia tabaci: A case study from North America. Crop Protection, 20 (9): 853-869. doi: 10.1016/S0261-2194(01)00116-8

Erdogan, C. Moores, D. G.; Gurkan, M. O.; Gorman, K. J.; Denholm, I. 2008. Insecticide resistance and biotype status of populations of the tobacco whitefly Bemisia tabaci (Hemiptera: Aleyrodidae) from Turkey. Crop Protection, 27; 600-605. doi: 10.1016/j.cropro.2007.09.002
Faria, J. C.; Bezera, I. C.; Zerbini, F. M.; Ribeiro, S. G.; Lima, M. F. 2000. Situação Atual Das Geminiviroses no Brasil. Fitopatologia Brasileira, $25: 125-137$

Faria, M.; Wraight, S. P. 2001. Biological control of Bemisia tabaci with fungi. Crop Protection, 20 (9): 767-778. doi: 10.1016/S02612194(01)00110-7

Martin, B.; Collar, J. L.; Tjallingii, W. F; Fereres, A. 1997. Intracellular ingestion and salivation by aphids may cause the acquisition and inoculation of non-persistently transmitted plant viruses. Journal of General Virology, 78 (10): 2701-2705. doi: 10.1099/0022-1317-7810-2701

Gadhave, K. R. Dutta, B.; Coolong, T.; Srinivasan, R. 2019. A nonpersistent aphid-transmitted Potyvirus differentially alters the vector and non-vector biology through host plant quality manipulation. Scientific Reports, 9 (1): 1-12. doi: 10.1038/s41598-019-39256-5

Gerling, D.; Horowitz, A. R. 1986. Baumgaertner, J. Autecology of Bemisia tabaci. Agriculture, Ecosystems and Environment, 17: 5-19.

Pakkianathan, B. C.; Kontsedalov, S.; Lebedev, G.; Mahadav, A.; Zeidan, M.; Czosnek, H.; Ghanim, M. 2015. Replication of Tomato Yellow Leaf Curl Virus in Its Whitefly Vector, Bemisia tabaci. Journal of Virology, 89 (19): 9871-9803. doi: 10.1128/JVI.00779-15

Ghanim, M.; Morin, S.; Czosnek, H. 2001. Rate of Tomato yellow leaf curl virus translocation in the Circulative Transmission Pathway of its Vector, the Whitefly Bemisia tabaci. Phytopathology, 91 (2): 188-196. doi: 10.1094/PHYTO.2001.91.2.188

Gibbs, A. J. Ohshima, K.; Phillips, M. J.; Gibbs, M; J. 2008. The Prehistory of Potyviruses: Their Initial Radiation Was during the Dawn of Agriculture. Plos One, 3 (6): e2523. doi: 10.1371/journal.pone.0002523

Gilbertson, R. L. Batuman, O.; Webster, C. G.; adkins, S. 2015. Role of the Insect Supervectors Bemisia tabaci and Frankliniella occidentalis in the Emergence and Global Spread of Plant Viruses. Annual Review of Virology, 2: 67-93. doi: 10.1146/annurev-virology-031413-085410

Glasa, M. Kúdela, O.; Marie-Jeanne, V.; Quiot, J. B. 2007. Evidence of a Naturally Occurring Recombinant Isolate of Plum pox virus from Slovakia. Plant Disease, 85 (8): 920-920. doi: 10.1094/PDIS.2001.85.8.920C

Gray, S.; Cilia, M.; Ghanim, M. 2014. Circulative, "Nonpropagative" virus transmission: An orchestra of virus-, insect-, and plant-derived instruments. Advances in Virus Research, 89:141-189. doi: 10.1016/ B978-0-12-800172-1.00004-5

Gray, S.; Gildow, F. E. L. 2003. Luteovirus-Aphid Interactions. Annual Review of Phytopathology, 41: 539-566. doi: 10.1146/annurev. phyto.41.012203.105815

Grover, S. Jindal, V.; Banta, G.; Taning, C. N. T.; Smagghe, G.; Christiaens, O. 2019. Potential of RNA interference in the study and management of the whitefly, Bemisia tabaci. Archives of Insect Biochemistry and Physiology, 100 (2): 1-17. doi: 10.1002/arch.21522

Gupta, V. 2012. Aphids on the world's crops. An identification and information guide. Oriental Insects, 35:104-104. doi: 10.1080/00305316.2001.10417292

Gusmão, M. R.; Picanço, M. C.; Zanuncio, J. c.; Silva, D. J. H.; Barrigossi, J. A. F. 2005. Standardised sampling plan for Bemisia tabaci (Homoptera: Aleyrodidae) in outdoor tomatoes. Scientia Horticulturae, 103 (4): 403-412. doi: 10.1016/j.scienta.2004.04.005

Hill, J. H.; Whitham, S. A. 2014. Control of Virus Diseases in Soybeans. Advances in Virus Research, 90: 355-390. doi: 10.1016/B978-0-12801246-8.00007-X 
Interação vírus/vetor para pulgões (Hemiptera: Aphididae) e mosca-branca (Hemiptera: Aleyrodidae)

Hogenhout, S. A.; Ammar, E-D.; Whitfield, A. E.; Redinbaugh, M. G. 2008. Insect Vector Interactions with Persistently Transmitted Viruses. Annual Review of Phytopathology, 46: 327-359. doi: 10.1146/annurev. phyto.022508.092135

Hoh, F; Uzest, M.; Drucker, M.; Plisson-Chastang, C.; Bron, P.; Blanc, S.; Dumas, C. 2010. Structural Insights into the Molecular Mechanisms of Cauliflower Mosaic Virus Transmission by Its Insect Vector. Journal of Virology, 84 (9): 4706-4713. doi: 10.1128/JVI.02662-09

Inoue-Nagata, A. K.; Navas-Castillo, J.; Melo, P. C. T.; Avila, A. C. de. 2006. Busca por Tomato yellow leaf curl virus e Tomato yellow leaf curl Sardinia virus em tomateiros. Horticultura Brasileira, 22 (4): 799-800. doi: 10.1590/S0102-05362004000400027.

Ivanov, K. I.; Eskelin, K.; Löhmus, A.; Mäkinen, K. 2014. Molecular and cellular mechanisms underlying potyvirus infection. Journal of General Virology, 95: 1415-1429. doi: 10.1099/vir.0.064220-0

Jacobson, A. L.; Duffy, S.; Sseruwagi, P. 2018. Whitefly-transmitted viruses threatening cassava production in Africa. Current Opinion in Virology, 33: 167-176. doi: 10.1016/j.coviro.2018.08.016

Kalleshwaraswamy, C. M.; Kumar, N. K. K. 2008. Transmission Efficiency of Papaya ringspot virus by Three Aphid Species. Phytopathology, 98 (5): 541-546. doi: 10.1094/PHYTO-98-5-0541

Kasprowicz, L.; Gaynor, M.; Jon, P.; Brian, F. 2008. Spatial and temporal dynamics of Myzus persicae clones in fields and suction traps. Agricultural and Forest Entomology, 10 (2): 91-100. doi: $10.1111 / \mathrm{j} .1461-9563.2008 .00365 . x$

Khajuria, C.; Ivashuta, S.; Wiggins, E.; Flagel, L.; Moar, W.; Pleau, M.; Miller, K.; Zhang, Y.; et al. 2018. Development and characterization of the first dsRNA-resistant insect population from western corn rootworm, Diabrotica virgifera virgifera LeConte. PLoS ONE, 13 (5): 1-19. doi: 10.1371/journal.pone.0197059

Krause-Sakate, R.; Fakhfakh, H.; Peypelut, M.; pavan, M. A.; Zerbini, F. M.; Marrakchi, M.; Candresse, T.; Le Gall, O. 2004. A naturally occurring recombinant isolate of Lettuce mosaic virus. Archives of Virology, 149: 191-197. doi: 10.1007/s00705-003-0201-y

Costa, E. M. R.; Marchese, A.; maluf, W.R.; Silva, A. A. 2014. Resistência de genótipos de couve-manteiga ao pulgão-verde e sua relação com a cerosidade foliar. Revista Ciência Agronômica, 45: 146-154.

Mauck, K. E.; Chesnais, Q.; Shapiro, L. R. 2018. Evolutionary Determinants of Host and Vector Manipulation by Plant Viruses. Advances in Virus Research. 101: 189-250. doi: 10.1016/bs.aivir.2018.02.007

Mauck, K. E.; De Moraes, C. M.; Mescher, M. C. 2014. Biochemical and physiological mechanisms underlying effects of Cucumber mosaic virus on host-plant traits that mediate transmission by aphid vectors. Plant, Cell and Environment, 37 (6):1427-1439. doi: 10.1111/pce.12249

Mauck, K.; Bosque-Pérez, N. A.; Eigenbrode, S. D.; De Moraes, C. M.; Mescher, M. C. 2012. Transmission mechanisms shape pathogen effects on host-vector interactions: Evidence from plant viruses. Functional Ecology, 26 (5): 1162-1175. doi: 10.1111/j.1365-2435.2012.02026.x

Mauck, K. E.; De Moraes, C. M.; Mescher, M. C. 2010. Deceptive chemical signals induced by a plant virus attract insect vectors to inferior hosts. Proceedings of the National Academy of Sciences, 107 (8): 3600-3605. doi: 10. 10.1073/pnas.0907191107

Meekes, E. T. M.; Fransen, J. J.; Van Lenteren, J. C. 2002. Pathogenicity of Aschersonia spp. against whiteflies Bemisia argentifolii and Trialeurodes vaporariorum. Journal of Invertebrate Pathology, 81: 1-11, doi: 10.1016/ S0022-2011 (02)00150-7
Miller, G. L.; Foottit, R. G. 2017. The Taxonomy of Crop Pests : The Aphids. Insect Biodiversity: Science and Society, 1: 627-639. doi: 10.1002/9781118945568.ch20

Moran, N. A. 1992. The Evolution Of Aphid Life Cycles. Annual Review of Entomology, 37: 321-348. doi: 10.1146/annurev.en.37.010192.001541

Moreno, A.; Tjallingii, W. F.; Fernandez-Mata, G.; Fereres, A. 2019. Communication Differences in the mechanism of inoculation between a semi-persistent and a non-persistent aphid-transmitted plant virus. Journal of General Virology, 2012: 662-667. doi: 10.1099/vir.0.0378870

Moriones, E.; Navas-Castillo, J. 2000. Tomato yellow leaf curl virus, an emerging virus complex causing epidemics worldwide. Virus Research, 71: 123-134. doi: 10.1016/S0168-1702 (00)00193-3

Naranjo, S. E.; Chu, C.-C.; Henneberry, T. J. 2003. Economic injury levels for Bemisia tabaci (Homoptera: Aleyrodidae) in cotton: impact of crop price, control costs, and efficacy of control. Crop Protection, 15 (8): 779-788. doi: 10.1016/S0261-2194 (96)00061-0

Nauen, R.; Denholm, I. 2005. Resistance of insect pests to neonicotinoid insecticides: Current status and future prospects. Archives of Insect Biochemistry and Physiology, 58 (4): 200-215, 2005. doi: 10.1002/ arch.20043

Navas-Castillo, J.; Fiallo-Olivé, E.; Sánchez-Campos, S. 2011. Emerging Virus Diseases Transmitted by Whiteflies. Annual Reveiew of Phytopathology, 49: 219-248. doi: 10.1146/annurevphyto-072910-095235

Ng, J. C. K.; Falk, B. W. 2006. Virus-Vector Interactions Mediating Nonpersistent and Semipersistent Transmission of Plant Viruses. Annual Review of Phytopathology, 44: 183-212. doi: 10.225./annurev. phyto.44.070505.143325

Ng, J. C. K.; Perry, K. L. 2004. Transmission of plant viruses by aphid vectors. Molecular Plant Pathology, 5 (6): 505-511. doi: 10.1111/j.13643703.2004.00240.x

Oliveira, M. R. V. de; Amancio, E.; Laumann, R. A.; Gomes, L de O. 2003. Natural enemies of Bemisia tabaci (Gennadius) B biotype and Trialeurodes vaporariorum (Westwood) (Hemiptera: Aleyrodidae) in Brasília, Brazil. Neotropical Entomology, 32 (1): 151-154. doi: 10.1590/ S1519-566X2003000100023.

Palumbo, J. C.; Horowitz, A. R.; Prabhaker, N. 2001. Insecticidal control and resistance management for Bemisia tabaci. Crop Protection, 20 (9): 739-765. doi: 10.1016/S0261-2194 (01)00117-X

Pirone, T., P.; Perry, K., L. 2002. Aphids : Non-persistent Transmission. Advances in Botanical Research, 36: 1-19. doi: 10.1016/S0065-2296 (02)36056-7

Quintela, E. D.; Abreu, A. G.; lima, J. F. dos S.; Mascarin, G. M.; Santos, J. B. dos. 2016. Reproduction of the whitefly Bemisia tabaci (Hemiptera: Aleyrodidae) B biotype in maize fields (Zea mays L.) in Brazil. Pest management science, 72 (1): 2181-2187. doi: 10.1002/ps.4259

Revers, F: García, J. A. 2015. Molecular biology of potyviruses. Academic Press, 92: 101-199. doi: 10.1016/bs.aivir.2014.11.006

Rojas, M. R.; Macedo, M. A.; Maliano, M. R.; Soto-Aguilar, M.; Souza, J. O.; Briddon, R. W.; Kenyon, L.; Bustamante, R. F. R. et al. 2018. World Management of Geminiviruses. Annual Review of Phytopathology, 56: 637-677. doi: 10.1146/annurev-phyto-080615-100327 
de Oliveira, A. M. E. et al.

Sheveleva, A.; Ivanoc, P.; Gasanova, T.; Osipov, G.; Chirkov, S. 2018. Sequence Analysis of Plum pox virus Strain C Isolates from Russia Revealed Prevalence of the D96E Mutation in the Universal Epitope and Interstrain Recombination Events. Viruses, 10 (9): 450. doi: 10.3390/ v10090450

Sicard, A.; Zeddam, J-L.; Yvon, M.; Michalakis, Y.; Gutiérrez, S.; Blanc, S. 2015. Circulative Nonpropagative Aphid Transmission of Nanoviruses: an Oversimplified View. Journal of Virology, 89 (19): 9719-9726. doi: 10.1128/JVI.00780-15

Silva, A. K. F; Santos, C. D. G.; Nascimento, A. K. Q. 2010. Transmissão de begomovírus de plantas daninhas para tomateiros pela moscabranca. Planta Daninha, 28 (3): 507-514. doi: 10.1590/S010083582010000300007

Singh, G.; Singh, R. 2016. Review Article Distribution of Aphis Spiraecola Patch 1914. International Journal of Recent Advances in Multidisciplinary Research, 3 (12): 2100-2111.

Siomi, H.; Siomi, M. C. 2009. On the road to reading the RNAinterference code. Nature, 457: 396-404. doi: 10.1038/nature07754

Srinivasan, R.; Alvarez, J. M.; Eigenbrode, S. D.; Bosque-pérez, N. A. 2009. Influence of Hairy Nightshade Solanum sarrachoides (Sendtner) and Potato leafroll virus (Luteoviridae: Polerovirus ) on the Host Preference of Myzus persicae (Sulzer) (Homoptera: Aphididae). Environmental Entomology, 35 (2): 546-553. doi: 10.1603/0046225X-35.2.546

Stansly, P. A.; Naranjo, S. E. 2010. Bemisia: Bionomics and Management of a Global Pest. New York, Springer. doi: 10.1007/978-90-481-2460-2

Stewart, L. R.; Medina, V.; Tian, T.; Turina, M.; Falk, B. W.; Ng, J. C. 2010. A Mutation in the Lettuce Infectious Yellows Virus Minor Coat Protein Disrupts Whitefly Transmission but Not In Planta Systemic Movement. Journal of Virology, 84 (23): 12165-12173. doi: 10.1128/JVI.01192-10
Syller, J. 2006. The roles and mechanisms of helper component proteins encoded by potyviruses and caulimoviruses. Physiological and Molecular Plant Pathology, 67 (3): 119-130, 2006. doi: 10.1016/j. pmpp.2005.12.005

Wang, L. L.; Wei, X. M.; Ye, X. D.; Xu, H. X.; Zhou, X. P.; Liu, S. S.; Wang, X. W. 2014. Expression and functional characterisation of a soluble form of Tomato yellow leaf curl virus coat protein. Pest Management Science, 70 (10): 1624-1631. doi: 10.1002/ps.3750

Whitfield, A. E.; Falk, B. W.; Rotenberg, D. 2015. Insect vector-mediated transmission of plant viruses. Virology, 479-480: 278-289. doi: 10.1016/j.virol.2015.03.026

Yu, X. D.; Liu, Z. C.; Huang, S. L.; Chen, Z. Q.; Sun, Y. W.; Duan, P. F.; Ma, Y. Z.; Xia, L. Q. 2016. RNAi-mediated plant protection against aphids. Pest Management Science, 72 (6): 1090-1098. doi: 10.1002/ps.4258

Zabala, M. de T.; Littlejohn, G.; Jayaraman, S.; Studholme, D.; Bailey, T.; Lawson, T.; Tillich, M.; Licht, D.; Bölter, B.; Delfino, L. 2015. Chloroplasts play a central role in plant defence and are targeted by pathogen effectors. Nature Plants, 1 (6): 15074. doi: 10.1038/NPLANTS.2015.74

Zhang, T.; Luan, J. B.; Qi, J. F.; Huang, C. J.; Li, M.; Zhou, X. P.; Liu, S. S. 2012. Begomovirus-whitefly mutualism is achieved through repression of plant defences by a virus pathogenicity factor. Molecular Ecology, 21 (5): 1294-1304. doi: 10.1111/j.1365-294X.2012.05457.x

Zhao, J.; Zhang, X.; Hong, Y.; Liu, Y. 2016. Chloroplast in plantvirus interaction. Frontiers in Microbiology, 7: 1565. doi: 10.3389/ fmicb.2016.01565

Zuñiga, E.; Guttierez, P. A.2002 Inverno com pulgões. Revista Cultivar, 2002 . 